\section{Cracking the Cracked Knuckle: A Medical Student's Take}

\section{To the Editor:}

It may be in genuine consideration for another's health, or it may be a selfish attempt to alter the behavior of another. Regardless, many have been warned that the continuation of this custom, whether it ranges from the casual offender to those bordering on ritualism, will inevitably suffer longterm sequelae. The old story that prolonged habitual knuckle-cracking leads to arthritis may now be considered a myth. In addition to an examination of the effect of this behavior, an attempt will be made to unravel or perhaps further tangle another issue: what is the cause of the sound created when one has cracked a knuckle?

The majority who have offered an explanation for the cause of the sound uphold that the "crack" can be explained by a collapse of synovial fluid vapor cavities that result from the negative pressure induced by metacarpal-phalangeal (MCP), proximal interphalangeal (PIP), or distal interphalangeal (DIP) joint distraction ${ }^{1}$. Authorities who have studied the effects of knuckle-cracking rely upon this common explanation; however, the paucity of evidence to support this theory is remarkable.

Some endorse what they believe to be a more anatomically appropriate explanation: when the MCP, PIP, or DIP joint is flexed or extended with the right amount of force, the annular and cruciate ligaments, which cover the fibrous synovial sheaths of these joints, snap back into their original location after being stretched over their joint during flexion. The recoil of these stretched ligaments causes an impact on the synovial sheath that is responsible for the sound we hear.

There are several questions that may elucidate either theory. First, why can some individuals crack their knuckles easily, while others cannot? There seems to be a period in which one "trains the joint" to initiate a "crack" when the joint is manipulated repeatedly in the same fashion. While neither theory seems to intuitively explain the issue, the following question shall be considered. What is likely to account for the "refractory period" of knuckle-cracking? That is, what is responsible for time needed in between cracking the same joint? Perhaps there a need for "reconsolidation" of synovial fluid, or the constituents of it, to reacquire a state that will allow the "collapse of synovial fluid vapor cavities" upon flexion. The second theory may provide a more plausible explanation. With stretching of the ligaments over the joint, it seems reasonable that the elastic tissue is in a stretched state and needs time to retighten before it will be ready for another crack.

Could a MCP, PIP, or DIP joint be cracked in a recently deceased individual, prior to the onset of rigor mortis? And if so, could the joint be cracked multiple times? It seems logical that should one be able to crack the knuckle of a recently deceased person, this would not rule out either theory. However, if subsequent cracks were possible, it will be left for the reader to speculate upon which theory would be supported.

The claim that cumulative damage occurs during knuckle-cracking is not without a plausible theory. Castallenos and Axelrod submit that the sudden, rapid increase in intrasynovial tension exposes the joint to high-impact mechanical stresses, and that these stresses are analogous to the mechanism responsible for the erosion of ship propellers and blades of hydraulic machinery ${ }^{2}$. One study has advanced this theory by examining MCP joints distracted using a motorized device, which simultaneously monitored the load on the joint and its extension ${ }^{3}$. The study concluded that the energy contained in a crack signal exceeded a known level needed to produce articular cartilage damage ${ }^{3}$.

Further, Castallenos and Axelrod examined 300 consecutive outpatients for a self-reported history of knuckle-cracking combined with an examination of hand function; 74 patients with a history of habitual cracking (mean 35-year history) were compared to 226 non-crackers for the prevalence of various hand-joint pathologies. No significant differences were found between the 2 groups $^{2}$. Swezey and Swezey ${ }^{4}$ utilized anteriorposterior hand radiographs to detect the presence of osteoarthritis between 13 knuckle crackers and 15 non-crackers, and found no significant differences between the 2 groups.

One report, although primarily anecdotal, merits mention. For 50 years, a rheumatologist, Dr. Donald Unger, cracked the knuckles of his left hand at least twice a day, and left those on the right as a control. After 50 years, the knuckles on the left were cracked at least 36,500 times, while those on the right cracked rarely and spontaneously. There was no arthritis in either hand, and no apparent differences between the 2 hands after 50 years ${ }^{5}$.

Despite raising more questions than providing answers, the discussion of the cause and effect of habitual knuckle-cracking remains relevant, as many patients may approach their physician with concerns related to this habit.

JOHN GAETANO, 77 Fifth Avenue, Apt. 5A, New York, New York 10003, USA. Address correspondence to Mr. Gaetano;

E-mail: john_gaetano@nymc.edu

\section{ACKNOWLEDGMENT}

Matthew Pravetz, PhD, Associate Professor, Department of Cellular Biology and Anatomy, New York Medical College; Iradge Argani, MD, Department of Pathology, New York Medical College, New York, New York, USA.

\section{REFERENCES}

1. Unsworth A, Dowson D, Wright V. Cracking joints - A bioengineering study of cavitation in the metacarpophalangeal joint. Ann Rheum Dis 1971;30:348-58.

2. Castallenos J, Axelrod D. Effect of habitual knuckle cracking on hand function. Ann Rheum Dis 1990;49:308-9.

3. Watson P, Kernohan WG, Mollan RA. A study of the cracking sounds from the metacarpophalangeal joint. Proc Inst Mech Eng [H] 1989;203:109-18.

4. Swezey RL, Swezey SE. The consequences of habitual knuckle cracking. West J Med 1975;122:377-9.

5. Unger DL. Does knuckle cracking lead to arthritis of the fingers? Arthritis Rheum 1998;41:949-50.

J Rheumatol 2009;36:11; doi:10.3899/jrheum.090530 